\title{
Delo gründet Tochtergesellschaft in China
}

Nach der Gründung einer Tochtergesellschaft Ende 2012 in Singapur hat Delo Industrie Klebstoffe nun mit Delo Industrial Adhesives (), Co. Ltd. in Shanghai eine weitere Unternehmensbasis im asiatischen Raum geschaffen.

C hina ist für Delo ein sehr wichtiger Absatzmarkt. Langjähriger Handelspartner ist Electronic Scientific Engineering Ltd. (ESE) mit Sitz in Hong Kong. „Dank der bewährten Zusammenarbeit mit unserem chinesischen Partner ESE sind wir dort seit über 10 Jahren erfolgreich. Wir freuen uns, mit Shanghai jetzt schon die zweite Tochtergesellschaft im asiatischen Raum zu haben," sagt Sabine Herold, Geschäftsführende Gesellschafterin des Unternehmens.
Die Tochtergesellschaft verfügt in Zukunft über Lagerkapazitäten für Klebstoffe und bietet Service für Geräte wie LED-Aushärtungslampen an. „Dadurch werden wir den Wünschen und Anforderungen unserer Kunden in China noch besser gerecht", so Sabine Herold weiter.

Delo ist weltweit aktiv und in 12 Ländern auf drei Kontinenten mit eigenen Mitarbeitern präsent. In Asien erwirtschaftet das Unternehmen rund ein Drittel des Umsatzes.

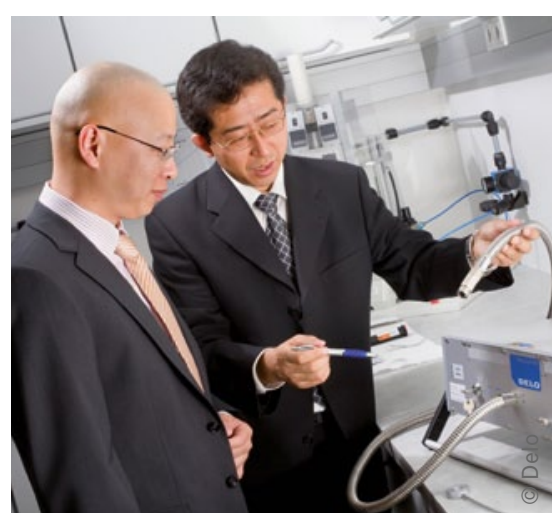

Delo hat jetzt eine zweite Tochtergesellschaft in Asien gegründet.

\section{Lanxess bündelt globales EPDM-Kautschukgeschäft}

Lanxess hat im niederländischen Sittard-Geleen den neuen Hauptsitz seines Geschäftsbereichs Keltan Elastomers eingeweiht und steuert ab sofort sein globales Geschäft mit Ethylen-Propylen-Dien-Monomer-Hochleistungskautschuken (EPDMKautschuke) von diesem Standort aus.

巨ür den neuen Hauptsitz des GeF schäftsbereichs Keltan Elastomers wurden auf einer Fläche von insgesamt $3.500 \mathrm{~m}^{2}$ Büroräume, Forschungslabore, Ausstellungsbereiche und Konferenzräume errichtet, die künftig von rund 125 Mitarbeitern genutzt werden. In der Architektur und bei der Wahl der Materialien wurde bewusst auf nachhaltige Lösungen gesetzt.

Lanxess investiert am niederländischen Standort derzeit zwölf Millionen Euro, um 50 Prozent seiner EPDM-Produktion auf die sogenannte Keltan ACETechnologie umzustellen. Mit ACE (Ad- vanced Catalyst Elastomers) kann - im Vergleich zu herkömmlichen Technologien - der Energiebedarf in der Herstellung erheblich reduziert werden. $\mathrm{Zu}$ dem ermöglicht das Verfahren die Herstellung neuer EPDM-Typen. Der Ausbau soll Mitte dieses Jahres abgeschlossen werden.

\section{Große Einsatzbreite}

Die in Sittard-Geleen hergestellten EPDM-Kautschuke werden vor allem in der Automobilindustrie, aber auch in der Baubranche und in technischen bzw. elektronischen Artikeln einge-

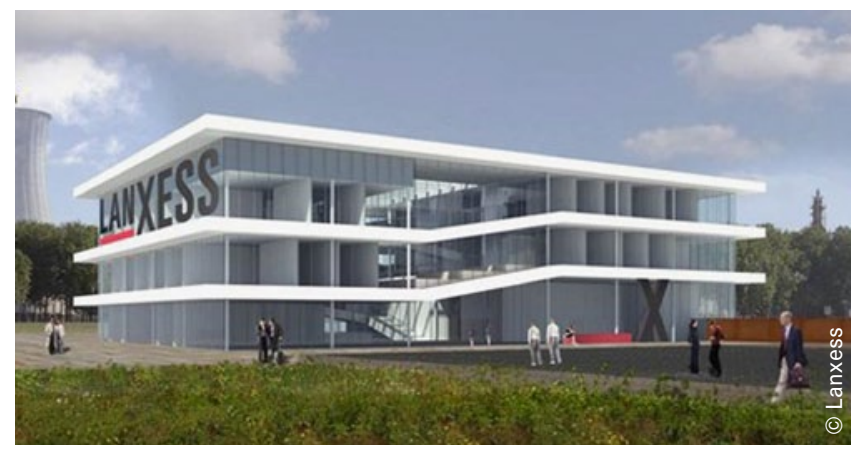

setzt. In Fahrzeugen werden die synthetischen Kautschuke, die sich vor allem durch ihre Beständigkeit gegen Hitze, Oxidation, Chemikalien und Witterung sowie durch gute Isoliereigenschaften auszeichnen, für Dichtungen in Karosserien bis hin zu Kühlmittelschläuchen unter der Motorhaube verwendet.

In der Bauwirtschaft kommt EPDMKautschuk ebenfalls vorwiegend als Dichtungsmaterial zum Einsatz - als Profildichtungen für Fenster und Türen, als Werkstoffe zum Dichten von Fugen, für Gummiplanen zum Abdecken von Flachdächern oder als Dichtungsprofile für Dachkonstruktionen aus Kunststoffplatten. Auch Dichtungen von Waschmaschinen, Badezimmerarmaturen oder Gartenschläuchen werden aus diesen Spezial-Kautschuken gefertigt.

Der Geschäftsbereich Keltan Elastomers gehört zum Lanxess-Segment Performance Polymers, das im Geschäftsjahr 2012 einen Umsatz von rund 5,2 Milliarden Euro erzielte. 